\title{
Effects of an Online-Blended Interprofessional Education Program on Graduate Students in Psychiatric Nursing, Exercise Physiology, Nutrition and Pharmacy: A Pilot Study
}

\author{
Lora Humphrey Beebe ${ }^{1}$, PhD, PMMHNP, BC, ${ }^{2}$ Marian Roman, PhD; ${ }^{3}$ Gary Skolits, PhD; \\ ${ }^{4}$ Hollie Raynor, PhD, RD, LDN; ${ }^{5}$ Dixie Thompson, PhD; ${ }^{6}$ Shaunta Ray, PharmD; \\ ${ }^{1}$ Professor \& Coordinator, Psychiatric Mental Health Graduate Concentration \\ ${ }^{2}$ Nursing, University of Tennessee Knoxville USA \\ ${ }^{3}$ Education, University of Tennessee Knoxville USA \\ ${ }^{4}$ Nutrition, University of Tennessee Knoxville USA \\ ${ }^{5}$ Exercise Physiology, University of Tennessee Knoxville USA \\ ${ }^{6}$ Pharmacy, University of Tennessee Knoxville USA
}

\begin{abstract}
:
Introduction: This article reports a pilot of the Recovery-Based Interprofessional Distance Education (RIDE) rotation - an interprofessional education (IPE) experience for graduate psychiatric mental health nurse practitioner, pharmacy, nutrition and exercise physiology students. The program was offered in a blended format, with online content enhanced by a 3 day, team-based clinical intensive experience.
\end{abstract}

Methods: In this pilot, participants ( $\mathrm{N}=12$ ) completed pre and post assessments before and after the experience.

Results: Pretest scores on the benefits of team training and contributing insight to teams were high with pretest means of 4.7 and 4.5 respectively. The experience did not change participants' perception of team training benefits, nor their perception that they could contribute valuable insights to teams, but attitudes about offering assistance to team members were improved. Student participation and these preliminary results indicate that offering an IPE program in an online blended format is feasible and acceptable to both graduate students and faculty.

Discussion: These results suggest that an IPE program can enhance practical, team-based skills in graduate nursing, pharmacy, nutrition and exercise physiology students and can be feasibly delivered using an onlineblended approach.

Conclusions: More research is needed examining formal IPE programs in graduate curricula, and the sustainability of such programs.

Acknowledgement: This project was supported by the Health Resources and Services Administration, HRSA Grant number: D09HP25932-02-01

\section{INTRODUCTION}

A large body of research demonstrates the high return on investment in terms of patient safety and quality of interprofessional practitioner education (IPE). It is less than ideal when practitioner students from different professions are educated in "silos" of their own disciplines and then expected to safely practice quality healthcare as a cohesive team (Irby, 2012).Many thought leaders propose we address new models of health practitioner education. In the Lancet report, Health Professionals for a New Century: Transforming Education to Strengthen Health Systems in an Interdependent World (Frenk, et al, 2011) there is a call to redesign instructional and educational strategies to improve health outcomes. Further, the establishment of the Core Competencies for Interprofessional Practice (Interprofessional Education-IPE Collaborative Expert Panel, 2011) set a direction for team-based practitioner education that will promote better transition for graduates into team-based care. IPE "occurs when two or more professions learn about, from and with each other to enable effective collaboration and improve health outcomes" (World Health Organization-WHO, 2010, p. 13). IPE is rapidly gaining ground in undergraduate

\footnotetext{
${ }^{1}$ Corresponding Author: lbeebe1@utk.edu
} 
programs in the health professions (Thibault, 2012) but is much less common in graduate practitioner education (Curran, Heath, Kearney \& Burton, 2010).

\section{BACKGROUND}

We found no published reports of IPE in graduate psychiatric mental health nurse practitioner programs, however one publication was located that included graduate family nurse practitioner students. Hanyok, et al (2013) conducted a graduate-level IPE program with (number of students not specified) adult nurse practitioner and internal medicine resident students. First, students participated in face-to-face classroom and small group sessions over one month. The experience culminated in three sessions of face-to-face patient care in a primary care setting. These authors reported significant improvements in teamwork skills $(\mathrm{p}<0.001)$, understanding of professional roles $(\mathrm{p}<$ $0.001)$ and conflict management $(\mathrm{p}<0.001)$ after the program. Participating students placed higher value upon the "real life" IPE experience than the classroom based activities.

Until now there has been little opportunity for team-based education at the University Of[...]. Although advanced practice nursing, exercise physiology, nutrition and pharmacy students are currently being educated within a short distance of each other, until recently there has been no effort to bring these students together for IPE. This project constitutes the first educational collaboration between these practitioner programs. Interprofessional education is a natural fit for graduate psychiatric mental health nursing, since many psychiatric disorders are associated with health barriers (sedentary lifestyle, poor nutrition-Author, 2005) that are amenable to intervention by a variety of disciplines. A faculty team of two psychiatric nurse practitioners, an exercise physiologist, a registered dietician and a pharmacist developed the 8-week Recovery-Based Interprofessional Distance Education (RIDE) program for graduate students in our four disciplines.

\subsection{Purpose}

The purpose of this pilotwas to examine the feasibility and acceptability of an online-blended IPE program, and to gather preliminary data about the effect of the program upon attitudes about IPE, perceived benefits of IPE and specific IPE skills.

\subsection{The RIDE program}

RIDE faculty designed an online-blended IPE program using distance technology, and collaborated on all content and delivery methods, student activities and grading rubrics. For five weeks, faculty and students interacted for two hours each week via synchronous online distance sessions using Blackboard Collaborate. Weeks one and two focused on IPE and the recovery model, respectively. During weeks three and four, student teams viewed and discussed online videos of simulated patient interactions with the various professions. At week 5 student teams interacted "live" with a mock patient via video conferencing. During week 6, students provided in-person care during a clinical intensive at a community mental health center (CMHC) over 3 days. The CMHC is a regional, not for profit integrated system providing care to 6500+ persons with mental health and substance use disorders in 19 counties in the southeastern United States. Student teams provided recovery-based assessments and collaborated with patients to produce a plan of care for a patient-identified recovery goal.

\section{METHODS}

\subsection{Study Design and Setting}

A quasi experimental pretest posttest design was used with a convenience sample of participants surveyed pre- and post- RIDE. Since RIDE was incorporated into required coursework, completion of didactic/clinical activities was mandatory as part of the required coursework while completion of pre- and post- measures for this research was voluntary. In this manuscript, we refer to the 19 persons who completed only the RIDE activities required for coursework as students. We refer to those who completed both RIDE activities required for coursework and RIDE pre- and post- assessments, as participants $(\mathrm{N}=12)$.

\subsection{Sample}

Following the granting of approval from the University of [...] Institutional Review Board (IRB), our 19 students were emailed details regarding the pre-and post-assessments, and online question and answer sessions were conducted with all students prior to the granting of consent.

\subsection{Instruments}


Once informed consent was obtained, participants $(\mathrm{N}=12)$ completed the Team Strategies and Tools to Enhance Performance and Patient Safety-Teams EPPS Teamwork Attitudes Questionnaire (T-TAQ) anonymously online (Baker, Krokos \& Amodeo, 2008). Following the week 6 clinical intensive, participants $(\mathrm{N}=12)$ repeated the $\mathrm{T}$ TAQ anonymously online.

The T-TAQ is a 30 item Likert-type scale that includes six items for each team construct: team structure, leadership, situation monitoring, mutual support and communication. Responses range from $1=$ strongly disagree to $5=$ strongly agree. Four items are reverse scored: mutual support items 20,21, 24 and communication item 30. A total score may be calculated for each construct (range 6-30) and an average score derived. The developers report the following Cronbach's Alpha for the team constructs: team structure: 0.7, leadership: 0.81, situation monitoring: 0.83, mutual support: 0.7 and communication 0.74(Baker, Krokos \& Amodeo, 2008).

\subsection{Data Analysis}

Data analysis consisted of data plots and basic descriptive statistics, such as frequency distributions, means and standard deviations, appropriate for the level of measurement of the variables. Due to the small sample size, this pilot analysis is descriptive only.

\section{RESULTS}

A total of 19 students participated (11 nursing, 4 pharmacy, 2 nutrition and 2 exercise physiology) and 12 participants completed both pre and post- measures ( 6 nursing, 2 pharmacies, 2 nutrition and 2 exercise physiology). Table 1 summarizes the demographic characteristics of the 12 participants completing both pre and posttest measures.

Table1. Demographic Characteristics of students completing pre assessment $(n=12)$.

\begin{tabular}{|c|c|c|}
\hline Characteristic & Frequency ( n ) & Percent (\%) \\
\hline \multicolumn{3}{|l|}{ Program } \\
\hline Psychiatric Nurse Practitioner & 6 & 50 \\
\hline Exercise Physiologist & 2 & 16.6 \\
\hline Nutritioist & 2 & 16.6 \\
\hline Pharmacist & 2 & 16.6 \\
\hline \multicolumn{3}{|l|}{ Sex } \\
\hline Female & 8 & 66.6 \\
\hline Male & 4 & 33.3 \\
\hline \multicolumn{3}{|l|}{ Race } \\
\hline White/Caucasian & 8 & 66.6 \\
\hline Black/African American & 3 & 25 \\
\hline Hispanic/Latino & 1 & 8.3 \\
\hline \multicolumn{3}{|c|}{ Healthcare experience prior to entering program } \\
\hline Yes & 8 & 66.6 \\
\hline No & 4 & 33.3 \\
\hline
\end{tabular}

Scores for the constructs team structure, leadership, situation monitoring and communication ranged from 3-5 while scores for mutual support ranged from 1-5. Pre and post means for selected T-TAQ construct items, along with pre and post RIDE differences, are presented in table 2.

Table2. Pre and post means for selected T-TAQ construct items $(N=12)$

\begin{tabular}{|c|c|c|c|}
\hline Construct & $\begin{array}{l}\text { Pre-test } \\
\text { Mean }\end{array}$ & $\begin{array}{l}\text { Post-test } \\
\text { Mean }\end{array}$ & $\begin{array}{l}\text { Mean } \\
\text { difference }\end{array}$ \\
\hline $\begin{array}{l}\text { Team Structure } \\
\text { It is important to ask patients and their families for feedback regarding } \\
\text { patient care }\end{array}$ & 4.62 & 4.69 & 0.07 \\
\hline Patients are a critical component of the care team & 4.85 & 4.92 & 0.07 \\
\hline This facility's administration influences the success of direct care teams & 4.15 & 4.31 & 0.16 \\
\hline $\begin{array}{l}\text { Situation Monitoring } \\
\text { Monitoring patients provides an important contribution to effective } \\
\text { team performance }\end{array}$ & 4.38 & 4.54 & 0.16 \\
\hline
\end{tabular}




\begin{tabular}{|c|c|c|c|}
\hline $\begin{array}{l}\text { It is appropriate for one team member to offer assistance to another } \\
\text { who may be too tired or stressed to perform a task }\end{array}$ & 4.0 & 4.23 & 0.23 \\
\hline $\begin{array}{l}\text { Mutual Support } \\
\text { It is appropriate to continue to assert a patient safety concern until you } \\
\text { are certain that it has been heard }\end{array}$ & 4.46 & 4.54 & 0.08 \\
\hline Personal conflicts between team members do not affect patient safety & 1.77 & 2.08 & 0.31 \\
\hline
\end{tabular}

Table3. Pre and post response means for the $T-T A Q(N=12)$

\begin{tabular}{|l|l|l|l|}
\hline Question & $\begin{array}{l}\text { Pre-test } \\
\text { Mean }\end{array}$ & $\begin{array}{l}\text { Post-test } \\
\text { Mean }\end{array}$ & $\begin{array}{l}\text { Mean } \\
\text { difference }\end{array}$ \\
\hline How familiar are you with working as part of an interprofessional team? & 3.46 & 4.07 & 0.61 \\
\hline How familiar are you with training as part of an interprofessional team? & 2.26 & 3.96 & 1.7 \\
\hline $\begin{array}{l}\text { Learning with other students helps me become a more effective member of } \\
\text { a health care team }\end{array}$ & 4.31 & 4.31 & $-0-$ \\
\hline $\begin{array}{l}\text { Patients ultimately benefit if interprofessional healthcare students learn } \\
\text { together to solve patient problems }\end{array}$ & 4.69 & 4.69 & $-0-$ \\
\hline $\begin{array}{l}\text { Interprofessional healthcare team training exercises help me appreciate } \\
\text { other professionals }\end{array}$ & 4.15 & 4.15 & $-0-$ \\
\hline $\begin{array}{l}\text { I enjoy learning opportunities that bring together students form other } \\
\text { professions }\end{array}$ & 4.08 & 4.15 & 0.07 \\
\hline $\begin{array}{l}\text { I perform well in settings that bring together students from other } \\
\text { professions }\end{array}$ & 3.92 & 4.15 & 0.23 \\
\hline I can work effectively in teams & 4.46 & 4.54 & 0.08 \\
\hline I can contribute valuable insight to teams & 4.38 & 4.54 & 0.17 \\
\hline I can easily facilitate communication between team members & 4.08 & 4.38 & 0.3 \\
\hline I can effectively coordinate tasks and activities of a team & 3.77 & 4.38 & 0.61 \\
\hline I am able to resolve conflict between team members effectively & 3.77 & 4.23 & 0.46 \\
\hline $\begin{array}{l}\text { It is important to ask patients and their families for feedback regarding } \\
\text { patient care }\end{array}$ & 4.62 & 4.69 & 0.07 \\
\hline Patients are a critical component of the care team & 4.85 & 4.92 & 0.07 \\
\hline It is important for leaders to share information with team members & 4.77 & 4.77 & $-0-$ \\
\hline $\begin{array}{l}\text { Effective leaders view honest mistakes as meaningful learning } \\
\text { opportunities }\end{array}$ & 4.54 & 4.54 & $-0-$ \\
\hline $\begin{array}{l}\text { Monitoring patients provides an important contribution to effective team } \\
\text { performance }\end{array}$ & 4.38 & 4.54 & 0.16 \\
\hline It is appropriate for team members to offer assistance to one another & 4.00 & 4.5 & 0.5 \\
\hline
\end{tabular}

\section{CONCLUSIONS}

To our knowledge, this is the first report of an IPE program including graduate psychiatric nurse practitioner, exercise physiology, pharmacy and nutrition students. These preliminary data indicate an increase in perceived value of situation monitoring, mutual support and team structure.

Our findings echo to those of Hanyok, et al (2013) in that our students reported increases in the teamwork constructs of communication and assisting team members. Further, both our findings and those of Hanyok indicate gains in the value of asserting concerns, and the realization that conflict between team members can affect patient safety.

Despite high pre- test scores, the post- assessment reflected growth in some areas. Pre-post assessments reflected areas of participant sophistication and some areas of growth related to team structure, situation monitoring and mutual support. In particular, team structure demonstrated gains in perceived value of patient and family feedback, perception of patients as critical members of the care team, and the importance of administrative support for team success. In regard to situation monitoring, participants demonstrated increases in perceived value of patient monitoring and assisting team members. Finally, the construct of mutual support showed improvement in asserting patient safety concerns. 


\section{American Research Journal of Nursing, Volume 1, Issue 3, September 2015 ISSN 2379-2922}

Limitations of this project include the small numbers of students participating, the lack of pre- and post- measures from all RIDE students, and unequal representation on teams due to greater numbers of nursing graduate students than other disciplines.

These preliminary results have implications for faculty desiring to offer graduate IPE experiences, particularly using online-blended delivery methods. While 19 students participated in RIDE activities, only 12 (63\%) completed the pre and post assessments for this pilot. Some students reported confusion between the student role and their role as research participants. Faculty desiring to offer IPE content, and to publish the results, should take care to provide written and in-person verbal explanations to students prior to project start up. Small financial or other incentives for completion of questionnaires could also be considered. Based on our preliminary observation of very high T-TAQ scores (Baker, Krokos \& Amodeo, 2008), we suggest that this measure may not be ideal for graduate students. Results from this small pilot sample suggest that T-TAQ items measure skills and values that many graduate students have already mastered. For this reason, we recommend the use of measures specifically targeted to individual team development to measure the effects of IPE with graduate students (Stock, Mahoney \& Carney, 2013). Finally, the use of online-blended technology was a barrier for some students and faculty. We suggest formal training in online technology be offered to both students and faculty before using this method for IPE offerings. Details of our start-up procedures and training activities have been published elsewhere (Author al, in press)

These preliminary results suggest that an IPE program can enhance some team concepts and skills in graduate nursing, pharmacy, nutrition and exercise physiology curricula, and can be feasibly delivered in an online-blended format. Future projects will specifically examine the impact of distance education technology on student experiences of IPE and recovery-based education.

\section{ACKNOWLEDGEMENT}

This project was supported by the Health Resources and Services Administration, HRSA Grant number: D09HP25932-02-01

\section{REFERENCES}

[1] Author, et al (in press). The Recovery-Based Interprofessional Distance Education (RIDE) Rotation: Content and Rationale. Issues in Mental Health Nursing.

[2] Author (2005). Effects of exercise on mental and physical health parameters of persons with schizophrenia. Issues in mental Health Nursing, 26,661-676.

[3] Baker, D.P., Krokos, K.J., \& Amodeo, A.M. (2008). Team STEPPS Teamwork Attitudes Questionnaire Manual. U.S. Department of Defense: Washington, DC

[4] Curran V, Heath O, Kearney A., Burton P. (2010). Evaluation of an interprofessional collaboration workshop for post graduate residents, nursing and allied health professionals. Journal of Interprofessional Care, 24, 215231.

[5] Frenk J., Chen L., Bhutta, Z.A.Cohen, J., Crisp, N., Evans, T., Fineburg, H., Garcia, P., Ke, Y., Kelly, P., Kistnasamy, B., Meleis, A., Naylor, D., Pablos-Mendez, A., Reddy, S., Scrimshaw, S., Sepulveda, J., Servadda, D., \& Zurayk, H. (2010) Health professionals for a new century: transforming education to strengthen health systems in an interdependent world. Lancet, 383, 1341-1345.

[6] Hanyok LA, Walton-Moss B, Tanner E, Stewart R, Becker K. (2013). Effects of a graduate level interprofessional education program on adult nurse practitioner student and internal medicine resident physician attitudes toward interprofessional care. Journal of Interprofessional Care, 27: 526-528.

[7] Interprofessional Education Collaborative Expert Panel. (2011). Core competencies for interprofessional practice: Report of an expert panel. Interprofessional Education Collaborative: Washington, DC.

[8] Irby D. (2012, April). Impressions Learned and Next Steps Panel. Proceedings of the Conference on Interprofessional Education. Alexandria, VA: USA

[9] Stark, R., Mahoney, E. \& Carney, L. (2013). Measuring team development in clinical care settings. Family Medicine, 45(10), 691-700.

[10] Substance Abuse and Mental Health Services Administration. (2012). SAMHSA's Working Definition of Recovery: [http://www.samhsa.gov/recovery]

[11] Thibault G.(2012). Interprofessional education in the USA: Current activities and future directions. Journal of Interprofessional Care, 26,440-441. 
American Research Journal of Nursing, Volume 1, Issue 3, August 2015

ISSN 2379-2922

[12] World Health Organization. (2001). Mental health: New understanding, new hope. World Health Organization: Geneva, Switzerland.

\section{Author's Biography}

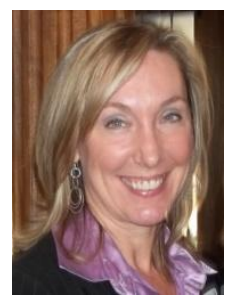

Dr Beebe is professor and coordinator of the psychiatric mental health graduate concentration at the University of Tennessee, Knoxville TN (UTK). She is the principal investigator for the federally funded grant referenced in the foregoing manuscript, and led the development of the first interprofessional collaboration between the departments of nursing, pharmacy, nutrition and exercise physiology at UTK. Her clinical research focus is the development and testing of community based treatments to foster physical and mental health in persons with schizophrenia spectrum disorders. 